\title{
Analysis of Material Metabolism of Eco-Economic System in Chongqing Based on the Emergy Theory
}

\author{
Gao Xue-song ${ }^{1,2}$, Luo Xiao-jiao ${ }^{3}$, Deng Liang-ji ${ }^{1,2}$, Zeng Min ${ }^{1}$ \\ ${ }^{1}$ College of Resourses and Environment, Sichuan Agricultural University, Ya'an, China; ${ }^{2}$ Center for Rural Development Research, \\ Ya'an, China; ${ }^{3}$ College of Architecture, Southwest Jiaotong University, Chengdu, China. \\ Email: mxl-789@163.com,359623545@qq.com
}

Received December $3^{\text {rd }}$, 2010; revised December 29 $9^{\text {th }}$, 2010; accepted January $10^{\text {th }}, 2011$.

\begin{abstract}
Based on the emergy theory proposed by H. T. Odum, the material metabolism of eco-economic system in Chongqing during 2002 2007 is analyzed. The results show that 1) the total available emergy in Chongqing is quite abundant and the economy is relatively more developed; the total metabolic output in Chongqing in 2007 was approximately $70 \%$ of its total metabolic input and both are increased, with an annual growth of $7.07 \%$ and $14.3 \%$ respectively; 2) the decreasing trend of most emergy efficiency indexes including system emergy self-sufficiency rate, emergy waste rate and emergy yield rate show that eco-economic system in Chongqing is still a resource consumption one, that the economic development mainly relies on local non-renewable resources, that the pressure of urban development on the environment keeps increasing and that the urban recycling capacity is yet to be improved; 3) the metabolic efficiency and metabolic intensity of the system are both increased, with an annual growth rate of $7.34 \%$ and $8.41 \%$ respectively; and 4) the environmental impact index of metabolism drops slowly, while the environmental loading ratio is large? fluctuating between 16.8 and 13.7. The prerequisite of achieving sound operation of the metabolic system in Chongqing lies in the regulation and control of the interactive relationship between metabolic fluxes so as to promote the coordinated symbiosis of urban metabolic emergy fluxes.
\end{abstract}

Keywords: Emergy Theory, Material Metabolism, Metabolic Flux, Metabolic Efficiency, Chongqing Municipality

\section{Introduction}

China's rapid industrialization and urbanization have aggravated the demand for natural resources and the environmental pollution. This extensive resource metabolism mode has increasingly obviously restricted the further development of the regional economy, and evaluation of the sustainable development of regional economy is urgently needed. The material metabolism analysis is to expound the demand of regional eco-economic system for resources and the pressure of waste emission on the system, based on the analysis of resource input and waste output. The metabolism analysis has increasingly become an important means to evaluate the soundness of ecoeconomic system [1,2]. The study of material metabolism analysis has, from its initial focus on single elements and basic raw materials, gradually emphasized the relationship among multiple metabolic processes, with study dimensions being increasingly widened [3]. The main study methods of metabolism analysis include material flow analysis (MFA), input-output analysis (IOA) and emergy analysis (EMA), etc. Some scholars hold that energy flow analysis is a vital way to comprehensively understand the metabolism of eco-economic system and may compensate for the disadvantages of material flow analysis [4,5]. Based on emergy analysis, many scholars have expounded the material flow and energy flow processes of eco-economic system and the system operation efficiency from different perspectives [6-8]. With Chongqing Municipality as an example, emergy theory is adopted in this paper to focus on the quantitative analysis of the metabolism of regional eco-economic system, diagnose the internal mechanism of resource and energy utilization and conversion, explore the optimal management mode of regional energy flow and the optimal energy use structure, provide theoretical guidance for selection of appropriate regional system metabolic mode, and offer measures and suggestions on promoting the sustainable development of Chengdu-Chongqing Growth Pole.

\section{Overview of the Region Under Study}

Chongqing, between North Latitude $28^{\circ} 10^{\prime}-32^{\circ} 13^{\prime}$ and 
East Longitude $105^{\circ} 11^{\prime}-110^{\circ} 11^{\prime}$, is located at a junction area between relatively-more-developed East China and resource-abundant West China, neighboring Hubei Province and Hunan Province in the east, Guizhou Province in the south, Sichuan Province in the west and Shaanxi Province in the north. As a region with a mid-subtropical humid monsoon climate, it is hot in summer and warm in winter, characterized by light and heat in the same season, long frost-free period, abundant rainfall as well as humid and frequent overcast days. Average temperature is $19.0^{\circ} \mathrm{C}$ and annual rainfall is $1439 \mathrm{~mm}$. With a total land area of $82400 \mathrm{~km}^{2}$, the altitude of Chongqing gradually lowers from north-south to the valley of the Yangtze River. Northwestern and central parts of Chongqing are mostly hilly areas and low mountainous areas. With 19 districts and 21 counties under administration, Chongqing boasts a total population of $3235.3 \times 10^{4}$ and GDP of RMB $4122.5 \times 10^{8}$ in late 2007. Chongqing is the largest economic center in the upper reach of the Yangtze River, a key industrial and commercial city in Southwest China and a hub of water and land traffic. In recent years, Chongqing has made a lot of beneficial explorations in developing circular economy and brought about huge economic, social and ecological benefits. However, the traditional growth mode of "large-quantity production, large-quantity consumption and large-quantity waste" has not been completely changed, and resource and environmental issues have increasingly become bottlenecks that restrain further economic advancement.

\section{Study Methods}

Based on the solar emergy conversion rates of various substances (energies), emergy analysis method is adopted to quantitatively analyze the energy flow in ecological system and economic system, and, through computation of various metabolic indexes, to scientifically and reasonably analyze and evaluate the regional material metabolism.

\subsection{Emergy Theory}

Emergy (unit: solar emjoules) is a concept developed from system ecology and eco-economics. The emergy theory is a method of quantitative analysis combining ecological system and economic system and according to the solar emergy conversion rates of various substances (energies) by regarding solar energy as the standard, in view of the fact that all energies originate from solar energy [8].

The emergy theory is to establish relations among different energy levels .and is to contact the economic system and ecological system of the bridge. Because it provides a common scale for measuring and comparing various energies, metabolic indexes of urban system are computed on this basis so as to scientifically and reasonably analyze and evaluate the urban system metabolism.

\subsection{Data Sources}

The original data adopted in this paper come from: Chongqing Statistical Yearbooks from 2003 to 2008 [9], Chongqing Statistical Communiqués on National Economic and Social Development, and the statistical data, statements and reports of relevant departments.

\subsection{Compilation of the Metabolic Emergy Table of Urban System}

First, main energy items of urban system metabolism in Chongqing during $2002 \sim 2007$ are listed, including renewable environmental resources, non-renewable environmental resources, renewable organic energies, nonrenewable industrial auxiliary energies, renewable resource product output and non-renewable resource product output, etc.; then, flow quantities of energies are obtained according to the energy computation formula, expressed as energy flow (J), material flow (g) and money flow (\$). After that, different energy units are converted into a unified emergy unit according to the emergy conversion rates of different resources so as to establish a metabolic emergy table of urban system in Chongqing (see Annex 1). All the solar emergy conversion rates and emergy computation formulas of substances (energies) in this paper are cited from the references [10-13].

\subsection{Evaluation Index System of Metabolic Emergy of Eco-Economic System}

Based on the original emergy evaluation index system $[5,6,9,10]$, the index system of metabolic analysis of eco-economic system in Chongqing is established from three perspective of metabolic emergy flux, emergy efficiency and metabolic evaluation. See Table 1 for the details.

\subsubsection{Analysis Index of Metabolic Emergy Flux}

Analysis indexes of metabolic emergy fluxes refer to the emergy fluxes of the system itself and the emergy fluxes of resource and service outputted from system metabolism [6], including emergy fluxes of metabolic input, metabolic output and metabolic waste of eco-economic system, which consist of 15 indexes (Table 1). Renewable resource emergy is numerically equal to the sum of renewable environmental resource and renewable organic energy, of which renewable environmental resource emergy input mainly consists of solar energy, wind energy, rain chemical energy, rain potential energy, heat from the Earth rotation, and timber, etc. As solar energy, wind energy, rain chemical energy and rain potential 
Table 1. Index system of emergy-based metabolic fluxes and metabolic analysis.

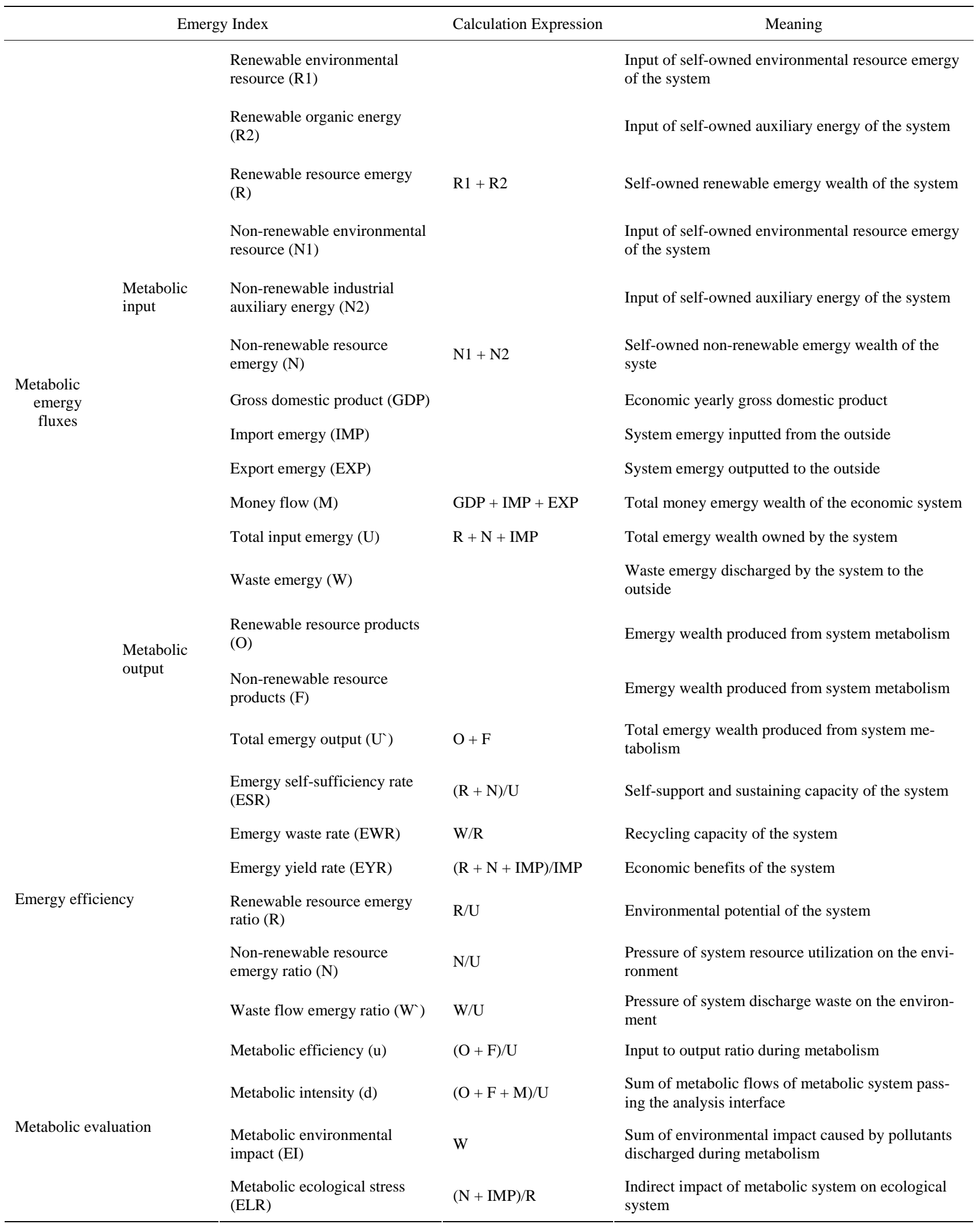

Note: All the indexes and calculation formulas in this table are cited from the references $[7,8,11,12]$. 
energy are compounds from the same process, only the maximum item of them is counted in the merging to avoid repeated computation. Non-renewable resource emergy is numerically equal to the sum of nonrenewable environmental resource and non-renewable industrial auxiliary energy. Non-renewable environmental resource emergy input is the sum of the emergy of all minerals, raw coal and natural gas, etc. and the emergy loss of surface soil layer. Import emergy of purchased resources of urban ecological system is noted as IMP; total emergy (U) means the total "wealth" of urban eco-economic system, which is numerically equal to the sum of the renewable and non-renewable resources of the system itself and the import emergy of the system. Non-renewable resource products mainly include raw coal, natural gas, steel materials, and aluminum materials, etc. Renewable resource products mainly include tap water, hydropower, agricultural products, animal products, and aquatic products, etc. Waste emergy (W) refers to the emergy of discharged pollutants, which is the sum of the emergy of waste water, waste gas and solid wastes.

\subsubsection{Analysis Index of Emergy Efficiency}

System emergy efficiency should include corresponding indexes reflecting economic efficiency, resource utilization efficiency and pollutant discharge efficiency. Evaluation indexes in this paper mainly include 6 items: emergy self-sufficiency rate (ESR), emergy waste rate (EWR), emergy yield rate (EYR), renewable resource emergy ratio ( $\left.\mathrm{R}^{\prime}\right)$, non-renewable resource emergy ratio (N') and waste emergy ratio (W'), among which, emergy self-sufficiency rate is used to evaluate utilization of self-owned resources of the system and self-support capacity of the system, emergy waste ratio is to evaluate availability of wastes discharged from the system and recycling capacity of the system, emergy yield rate is a kind of criterion to measure system operation efficiency, which is similar to the "output-input ratio" (output/input) in economic analysis, renewable resource emergy ratio reflects environmental potential of the system, and nonrenewable resource emergy ratio and waste emergy ratio represent the operation efficiency of regional system from perspectives of resource utilization and waste discharge respectively, which can be important indexes for metabolic emergy efficiency evaluation [6].

\subsubsection{Metabolic Evaluation Index}

China is in a rapid urbanization process. Production and consumption of resources not only support economic growth of cities/municipalities, but also influence ecological stress, environmental impact and sustainable development of public health, etc., making it imperative to evaluate regional sustainable development capacity through system metabolism. Evaluation indexes mainly include metabolic efficiency (u), metabolic intensity (d), metabolic environmental impact (EI) and metabolic ecological stress (ELR) [2,11]. Metabolic efficiency refers to the effective part of metabolic flows to the final user, basically defined as the input to output ratio during metabolism. Metabolic intensity is defined as the sum of metabolic flows of the system passing the analysis interface in a unit time, for which, the bigger the ratio is, the more complicated the structure of urban metabolic system is, the more perfect the storage system is, the more sufficient the feedback sector is, and the higher the integral stability and optimization degree of the system is. The essential difference between ecological stress and environmental impact lies in their different positions in metabolic system; the former is upstream end impact, while the latter is downstream end impact. Environmental impact in metabolic analysis is defined as the sum of environmental impacts of pollutants directly discharged during metabolic processes, while waste emergy (W) means the emergy of discharged pollutants, i.e. the sum of the emergy of waste water, waste gas and solid wastes. Thus metabolic environmental impact can be expressed in waste emergy. Operation of metabolic system not only leads to environmental impact that can be directly measured, but also produces a series of indirect impacts on regional and even global ecological systems, and these impacts together are collectively referred to as ecological stress. Due to difficulties in study methods, scale conversion and data acquisition, this paper adopts emergy environmental loading ratio index (ELR) to represent the pressure of metabolic activities on ecological system. When ELR $<3$, the environmental stress is small, when $3<\mathrm{ELR}<10$, the environmental impact is at an intermediate level; when ELR $>10$, the environmental stress is especially great [6].

\section{Results and Analysis}

Based on Chongqing Statistical Yearbooks from 2003 to 2008, Chongqing Statistical Communiqués on National Economic and Social Development and the statistical data, statements and reports of relevant departments [12], energy, material and money flow data in Chongqing from 2002 to 2007 are selected to analyze and evaluate the metabolism of Chongqing eco-economic system. After the original data are converted to a unified emergy unit and simplified and merged into each metabolic emergy flux, the emergy data are taken into the above calculation formulas of emergy efficiency and metabolic evaluation index, and the emergy evaluation table of metabolism of Chongqing Municipality in recent 6 years can be obtained (Table 2). 
Table 2. Metabolic emergy evaluation of chongqing municipality from 2002 to 2007.

\begin{tabular}{|c|c|c|c|c|c|c|}
\hline Item & Year 2002 & Year 2003 & Year 2004 & Year 2005 & Year 2006 & Year 2007 \\
\hline $\mathrm{R}\left(\times 10^{23} \mathrm{sej}\right)$ & 1.020 & 1.190 & 1.180 & 1.160 & 1.090 & 1.160 \\
\hline $\mathrm{N}\left(\times 10^{24}\right.$ sej $)$ & 1.380 & 1.380 & 1.580 & 1.770 & 1.740 & 1.930 \\
\hline IMP(×10² sej) & 0.776 & 1.050 & 1.750 & 1.780 & 2.130 & 2.950 \\
\hline $\operatorname{EXP}\left(\times 10^{22}\right.$ sej $)$ & 1.015 & 1.451 & 1.900 & 2.291 & 3.045 & 4.087 \\
\hline GDP $\left(\times 10^{23}\right.$ sej $)$ & 2.070 & 2.363 & 2.819 & 3.285 & 3.785 & 4.701 \\
\hline $\mathrm{M}\left(\times 10^{23}\right.$ sej $)$ & 2.250 & 2.360 & 3.180 & 3.690 & 4.300 & 5.400 \\
\hline $\mathrm{U}\left(\times 10^{24}\right.$ sej $)$ & 1.490 & 1.510 & 1.720 & 1.910 & 1.880 & 2.080 \\
\hline $\mathrm{W}\left(\times 10^{22}\right.$ sej $)$ & 2.600 & 2.590 & 2.530 & 2.810 & 2.654 & 2.247 \\
\hline $\mathrm{O}\left(\times 10^{22}\right.$ sej $)$ & 3.840 & 4.100 & 4.360 & 4.600 & 4.360 & 4.660 \\
\hline $\mathrm{F}\left(\times 10^{23}\right.$ sej $)$ & 7.060 & 8.040 & 8.500 & 9.940 & 12.000 & 14.000 \\
\hline $\mathrm{U}^{`}\left(\times 10^{23}\right.$ sej $)$ & 7.450 & 8.450 & 8.940 & 10.400 & 12.400 & 14.500 \\
\hline ESR & 0.995 & 0.993 & 0.990 & 0.991 & 0.989 & 0.986 \\
\hline EWR & 0.255 & 0.218 & 0.214 & 0.242 & 0.243 & 0.194 \\
\hline EYR & 192.000 & 144.000 & 98.000 & 107.000 & 88.000 & 70.500 \\
\hline $\mathrm{R}^{\prime}$ & 0.068 & 0.079 & 0.069 & 0.061 & 0.058 & 0.056 \\
\hline $\mathrm{N}^{`}$ & 0.927 & 0.914 & 0.921 & 0.920 & 0.930 & 0.930 \\
\hline$W^{-}$ & 0.017 & 0.017 & 0.015 & 0.015 & 0.014 & 0.011 \\
\hline $\mathrm{u}$ & 0.500 & 0.560 & 0.520 & 0.550 & 0.660 & 0.700 \\
\hline d & 0.649 & 0.718 & 0.710 & 0.740 & 0.900 & 0.960 \\
\hline $\mathrm{EI}\left(\times 10^{22}\right.$ sej $)$ & 2.600 & 2.590 & 2.530 & 2.810 & 2.654 & 2.247 \\
\hline ELR & 13.700 & 11.700 & 13.600 & 15.500 & 16.100 & 16.800 \\
\hline
\end{tabular}

Note: All data used for calculation in this table come from Chongqing Statistical Yearbooks from 2003 to 2008 [9], and all emergy conversion rates come from the references $[7,8,10-13]$.

\subsection{Metabolic Emergy Flux}

\subsubsection{Metabolic Input Analysis}

It is known from Table 2 that, the total emergy utilization in Chongqing eco-economic system is mainly nonrenewable resource emergy, which amounted to $92.3 \%$ of the total emergy in 2007, while renewable resource emergy and import emergy only occupied a small portion of the total emergy, accounting for $5.6 \%$ and $1.4 \%$ of the total emergy respectively in 2007. Non-renewable resource emergy mainly consists of emergy loss of surface soil layer, raw coal and natural gas, and the 3 items of emergy input account for $99.0 \%$ of the non-renewable resource emergy input. Landforms of Chongqing are mainly composed of mountainous areas. The severity of water and soil loss indicates over-intense development of non-renewable resource in Chongqing, indicates that the urban system development is still based on consumption of non-renewable fossil fuel and mineral matters. Hence, the utilization structure should be further improved to replace some non-renewable resources, thus to promote the sustainable development of Chongqing eco-economic compound ecological system.

From 2002 to 2007, renewable resource emergy, nonrenewable resource emergy and import emergy in ecoeconomic system of Chongqing were increased in general (Figure 1), with an annual growth rate of $2.9 \%$, $7.1 \%$ and $32.0 \%$ respectively. During the 6 years, money flow emergy and its composition were also increased. Money emery reached $5.40 \times 10^{23}$ sej in 2007 , with an annual growth rate of $19.6 \%$. Import emergy, export emergy and GDP emergy of Chongqing in 2007 were 3.8 times, 4 times and 2.3 times of those in 2002 respectively. Operation of eco-economic system metabolism in Chongqing mainly depends on input of local resources in the mass. Import emergy, compared with local resource emergy, is low, but its annual growth rate is obviously 
higher than that of local resource emergy, which shows that, as economy develops, regional metabolic system increasingly depends on external resources, and openness will be improved year by year. Thus, openness to the outside should be further improved, and external emergy should be extensively introduced to improve emergy feedback rate and alleviate resource stress of the region.

\subsubsection{Metabolic Output Analysis}

As waste utilization product emergy still appears in the form of renewable resource products and non-renewable resource products, the sum of renewable resource products and non-renewable resource products are taken as the total output of eco-economic system metabolism to avoid repetitive computation.

From 2002 to 2007, non-renewable resource products and total output emergy in the metabolic system of Chongqing were increased, increasing in 2007 to 1.98 times and 1.95 times of those in 2002 respectively, while renewable resource products increased slowly in fluctuation (Figure 2). The total output of metabolism in Chongqing varied mainly with the increase of non-renewable resource products. Non-renewable resource products accounted for $97.0 \%$ of the total metabolic output in 2007, which indicated that Chongqing metabolism still mainly depended on local non-renewable resource, and the renewable resource utilization was low, which needs to be strengthened.

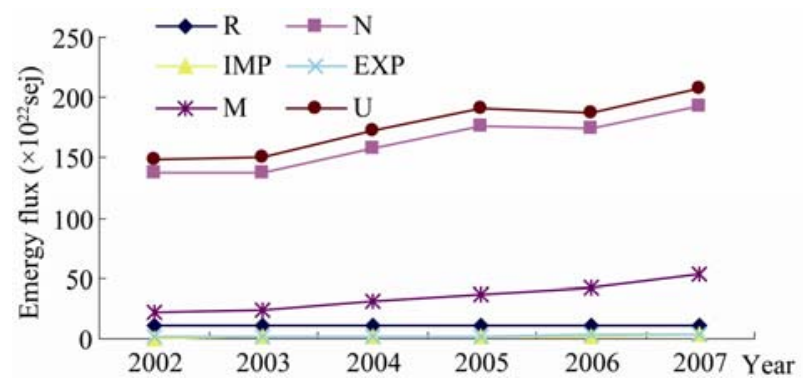

Figure 1. Change trend of metabolic emergy input in chongqing.

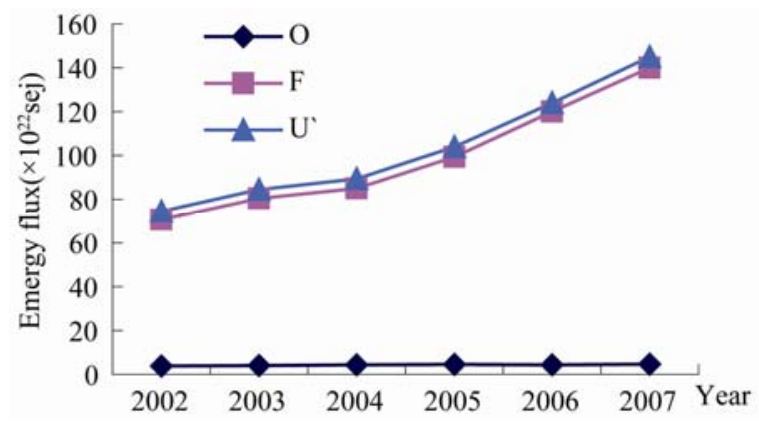

Figure 2. Change trend of metabolic emergy output in chongqing.
Metabolic input emergy and metabolic output emergy in Chongqing showed similar growth trends, while the average annual growth amount $\left(1.18 \times 10^{23}\right.$ sej $)$ and the average annual growth rate $(7.1 \%)$ of metabolic input were less than the average annual growth amount $(1.41 \times$ $10^{23}$ sej) and the average annual growth rate (14.3\%) of metabolic output. In 2007, the total metabolic output accounted for $70 \%$ of the total metabolic input, indicating that resource cycling utilization measures of Chongqing Municipality contributed to the alleviation of metabolic input of eco-economic system, and there had increasing trend in material inventory of the urban metabolic system.

\subsection{Emergy Efficiency Analysis}

From 2002 to 2007, introduction of external resources into Chongqing Municipality increased slowly, and system emergy self-sufficiency rate, emergy waste rate and emergy yield rate were obviously decreased in general (Figure 3(a)). During the 6 years, The openness of ecoeconomic system in Chongqing was not significant. System metabolism still greatly depended on internal resources. Emergy self-sufficient rate of the system was 98.6\% in 2007, a little lower than that in 2002 (99.5\%). Emergy waste rates of Chongqing were 25.5\%, 21.8\%, 21.4\%, 24.2\%, 24.3\% and 19.4\% respectively from 2002 to 2007, indicating that the level of waste-resource recycling in Chongqing was unstable during the 6 years, which requires further improvement of wastes treatment techniques. However, the overall level was still decreased slowly. With the development of environmentally-friendly technologies, the emergy waste rate is expected to further decrease. The emergy output rate was 192 in 2002, 2.7 times of that in 2007, indicating that the operation efficiency of regional metabolic system was not improved under the same economic emergy input. Renewable resource emergy ratio and waste emergy ratio were both decreased (Figure 3(b)), indicating that both the use of renewable resources and the pressure of waste discharge on environment in Chongqing decreased over the 6 years. Renewable resource emergy ratio increased significantly in 2003, mainly because the annual rainfall in renewable environmental resources and the human emergy in organic energy in 2003 were significantly higher than those in 2002 and 2004. Non-renewable resource emergy ratio was increased in general from 2003 to 2007, which showed that the operation efficiency of non-renewable resource utilization was strengthened during this period, while the utilization rate in 2002 was at a higher level, due to a relatively smaller total emergy of $1.49 \times 10^{24}$ sej.

The above analysis shows that eco-economic system in Chongqing still belongs to a resource consumption type. 


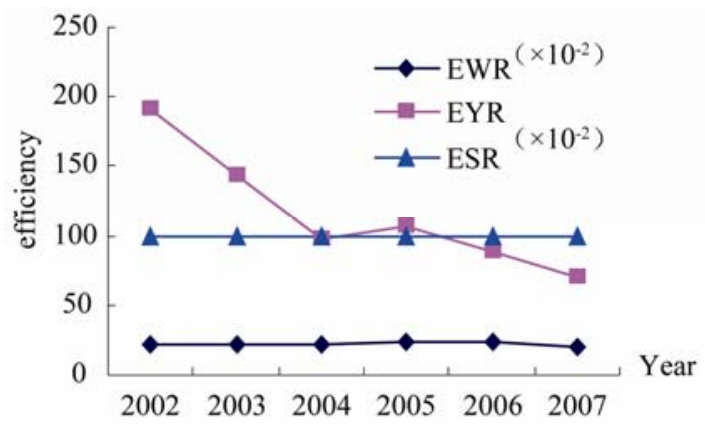

(a)

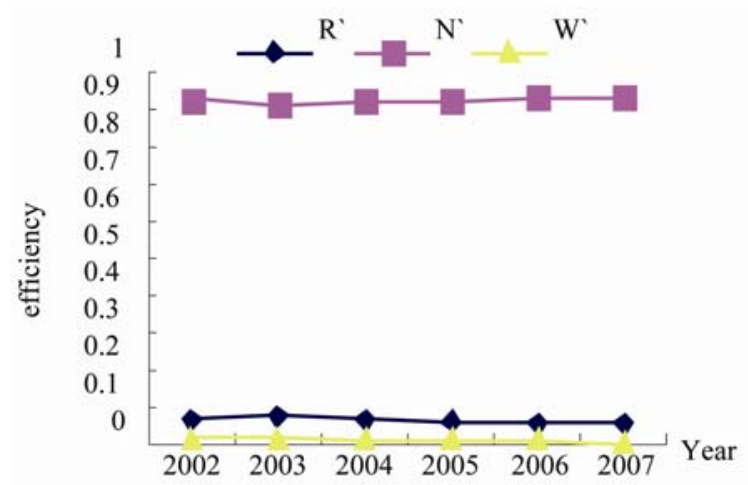

(b)

Figure 3. Emergy-based analysis of metabolic efficiency for urban system in Chongqing.

Economic development does not depend greatly on external factors. Due to increasing pressure of urban development on environment, the mode of economic growth needs to be changed, the industrial structure needs to be updated, and the resource supply and demand structure needs to be optimized. Specifically, utilization of nonrenewable resources in great quantities should be transformed into more dependence on input of renewable resources, so as to improve resource utilization rate and waste-resource recycling rate [15].

\subsection{Analysis of Metabolic Evaluation Indexes}

\subsubsection{Analysis of Metabolic Efficiency and Intensity}

Metabolic efficiency and metabolic intensity of ecoeconomic system in Chongqing from 2002 to 2007 showed similar growth tendencies (Figure 4). Those in 2007 were 1.4 times and 1.5 times of those in 2002 respectively, with an annual growth rate of $7.34 \%$ and $8.41 \%$ respectively, indicating that, with rapid economic development, metabolic efficiency and intensity were both higher than before; the effective part of metabolic process was also relatively strengthened during this period; the structure of metabolism system became increasingly complicated, the storage system was increasingly perfect, the feedback sector was increasingly sufficient, and the integral stability and optimization of the system was also relatively improved.

\subsubsection{Analysis of Metabolic Environmental Impact and Ecological Stress}

Metabolic environmental impact (EI) during the 6 years showed a trend from rising to dropping in the mass. Waste emergy did not change significantly compared to the rapid economic growth. Total amount of discharge of waste gas, water and residues in 2007 dropped slightly over that in 2002, i.e. $86.4 \%$ of that in 2002, indicating that Chongqing have paid much attention to the end-of-pipe treatment of industrial waste in recent years and the ecological environment has obtained increasing focus and improvement, while pollution treatment input and strength should be enhanced to improve environmental conditions.

The environmental loading ratio of eco-economic system in Chongqing was increased. The environmental loading ratio in 2007 was 1.23 times of that in 2002, indicating that the pressure of urban system in Chongqing on local environment was not weakened with the urban development (Figure 5). Environmental loading ratios over the 6 years were all higher than 10, fluctuating between 16.8 and 13.7. The operation of metabolic system in Chongqing has exerted significant indirect influence on upstream front-end of the ecological system. Although a

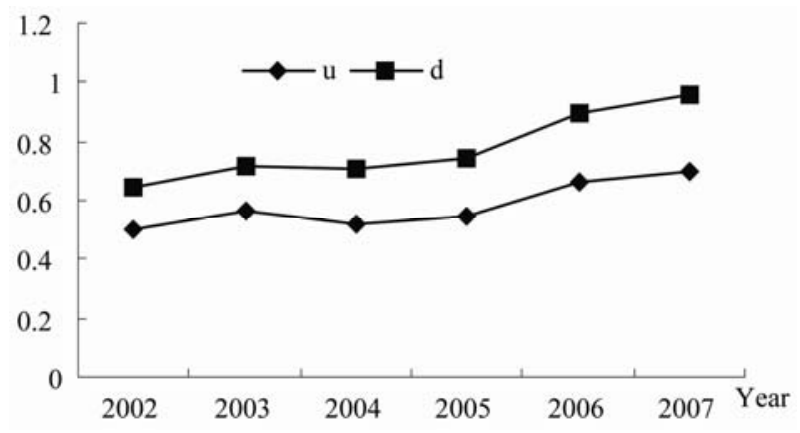

Figure 4. Development trends of system metabolic efficiency and intensity in chongqing.

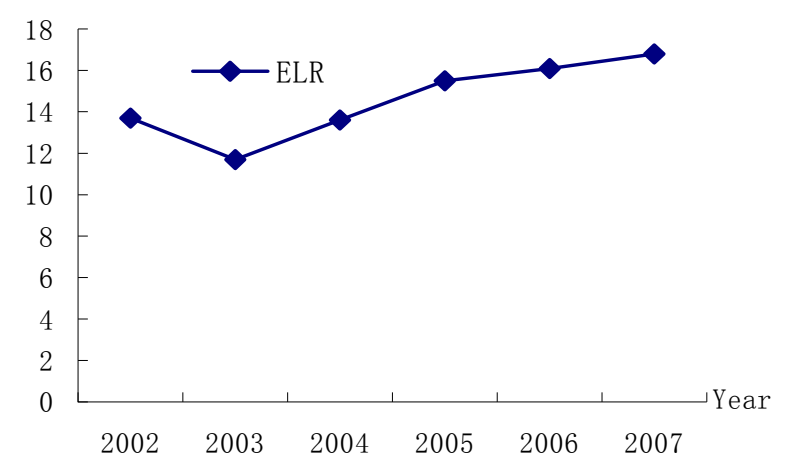

Figure 5. Development trend of metabolic ecological stress in chongqing. 
high environmental loading ratio indicates stronger system emergy utilization [16], the system will develop in a negative trend once the strong utilization exceeds the support threshold of the system. In the urban system of Chongqing, efforts should be made to maximize the utilization of local renewable resources and protect nonrenewable resources, such as sustainable utilization of mineral resources.

\section{Conclusions and Development Suggestions}

\subsection{Conclusions}

1) The total available emergy in Chongqing during 2002 2007 was quite abundant, and its annual growth and annual growth rate were $1.18 \mathrm{E}+23$ sej and $7.07 \%$ respectively, with higher economic development. Local renewable natural resources were relatively in shortage, mainly consisted of local non-renewable resources (accounting for $92.79 \%$ of the total emergy in 2007). It is learned from the above that the economic development mainly relies on internal resources, and is on the basis of high-intensity use of local resources. Therefore, as a whole, the urban system metabolism in Chongqing is relatively closed and the utilization degree of external emergy is low.

2) Metabolic output of the urban system of Chongqing and its structure were both increased. Its annual growth and annual growth rate were $1.41 \mathrm{E}+23$ sej and $14.3 \%$ respectively, both higher than the metabolic input emergy. This indicates that the recycling utilization and the resource recycling utilization of waste have made some contributions to alleviating the urban system metabolic input, and the material inventory of urban metabolic system is with net increase.

3) Money flow emergy of the urban system of Chongqing and its structure were both increased. The money emergy amount in 2007 reached 5.4E + 23sej, with an annual growth of $6.3 \mathrm{E}+22 \mathrm{sej}$ and an annual growth rate of $19.6 \%$. This indicates that, with development and status importance improvement of the economy in Chongqing, Chongqing will depend more and more on external environment, the input of external resources will keep growing, and the openness will rise year by year as well.

4) Indexes reflecting emergy efficiency were mostly decreased, among which, emergy self-sufficiency rate, emergy waste rate, emergy yield rate, renewable resource emergy ratio and waste emergy ratio in 2007 were 99\%, $76 \%, 37 \%, 82 \%$ and $62 \%$ of those in 2002 . By contrast, non-renewable resource ratio was fluctuating to rise. This indicates that, environmental impact of the waste discharged by the urban system on environment is turning better, but the urban system of Chongqing is a resource consumption one on the whole, and waste treatment techniques and resource utilization rate are yet to be improved.

5) Metabolic effect, metabolic efficiency and metabolic intensity of the urban system were keeping rising, with an annual growth rate of $14.3 \%, 7.34 \%$ and $8.41 \%$ respectively. The metabolic environmental impact was fluctuating to decrease. This indicates that the awareness of environmental protection and reasonable resource utilization is gradually improving and the self-organization capacity and development potential are both developing in an optimistic trend. However, the rising trend of metabolic ecological stress shows that the potential treat of resource consumption of Chongqing urban system upon the upstream end of the ecological system is gradually increasing. Therefore, only through reasonably regulating and controlling the interactive relationship between metabolic fluxes and through promoting the coordinated symbiosis of urban metabolic emergy fluxes can the sound operation of urban metabolic system be achieved.

\subsection{Suggestions on Sound Development of the Urban Metabolic System in Chongqing}

Currently, Chongqing should, based on its original development conditions, continuously introduce new technical innovative components, improve the utilization efficiency of input emergy, raise the emergy yield rate and waste-to-resource efficiency, reduce the system reliance on non-renewable resources, strengthen the development of renewable resources, and increase the social and economic benefits obtained from a unit environmental pressure so as to achieve sound cycling of system metabolism. The following should be done in order to achieve sound development of the urban system metabolism:

1) To improve system openness and enhance input of external emergy. Non-renewable resource emergy, renewable resource emergy and import emergy in Chongqing in 2007 were $92.79 \%, 5.58 \%$ and $1.42 \%$ respectively of the total emergy, indicating that environmental and resource pressures became increasingly obvious with the economic development. Despite a great annual growth rate (32\%) of the import emergy during 2002 2007, the total amount was small; thus, openness to the outside should be increased and external emergy (such as technologies, equipment and resources) should be extensively introduced to improve emergy feedback ratio, help emergy grow more rapidly and alleviate local resource pressure. Moreover, high-quality talents should be introduced in great numbers to improve talent structure and lay a human resource foundation for sound development of the system metabolism in Chongqing. 
2) To guide with policies, adjust the industrial structure and change the mode of economic growth. Since environmental loading ratios reflecting the metabolic ecological stress of Chongqing urban system all are higher than 10, fluctuating between 16.8 and 13.7, the government needs to consider how to protect environment and integrate macro-policy requirement of ecological factors while satisfying human needs. Besides, in the total emergy amount of Chongqing, non-renewable resource emergy accounts for the majority part, indicating that the economic growth in Chongqing mainly relies on the input of nonrenewable resources, in a mode of economic growth with high resource consumption, which seriously damages ecological and environmental resources and does not conform to the sustainable development concept in a harmonious society. Therefore, efforts should be made to adjust the industrial structure, change the mode of economic growth from extensive growth to intensive economy, rely on high technologies, utilize resources, well protect natural resources and ecological environment, improve comprehensive resource utilization efficiency and enlarge environmental capacity of regional development.

3) To develop educational system and promote commercialization of study output. Only through education can advanced technologies and experience with a great amount of creative emergy be converted and amplified into emergy and wealth to promote economic development and social progress.

4) To reasonably organize planning and vigorously develop tourism. The decrease trend of emergy yield rate in Chongqing indicates that Chongqing should strengthen industries with higher net emergy yield rates such as tourism, to make better advantages of natural and geographical environments and cultural scenery, and significantly promote local economy.

\section{REFERENCES}

[1] R. S. Halla, D. Shauna and A. K. Christopher, "Estimating the Urban Metabolism of Canadian Cities," Canadian Journal of Civil Engineering, Vol. 30, No. 2, 2003, pp. 468-483. doi:10.1139/102-105

[2] D. Li, J. R. Liu and R. S. Wang, "Progresses on the Analyzing Methods and Evaluating Indicators of Urban Ecosystems Metabolism,” Ecological Economy, No. 6, 2008, pp. 35-39.

[3] Q. F. Ma, X. J. Huang, S. T. Yu, et al., "Review on the
Research of Metabolism,” Journal of Natural Resources, Vol. 22, No. 1, 2007, pp. 141-152.

[4] H. Haberl, S. Batterbury and E. Moran, "Using and Shaping the Land: A Long-Term Perspective," Land Use Policy, Vol. 18, No. 1, 2001, pp.1-8. doi:10.1016/S0264-8377(00)00040-5

[5] W. Liu, M.T. Ju, Z. Li, et al., "Energy Flow Analysis in Regional (Urban) Environmental and Economic System," China Population, Resources and Environment, Vol. 18, No. 5, 2008, pp. 59-63.

[6] Y. Zhang and Z. F. Yang, "Emergy Analysis of Urban Material Metabolism and Evaluation of Eco-efficiency in Beijing,” Acta Scientiae Circumstantiae, Vol. 27, No.11, 2007, pp. 182-189.

[7] J. Zhou, A. G. Qi, D.Y. Yuan, et al., "Emergy Analysis of Eco-economic Systems of Hunan Province," Chinese Journal of Eco-Agriculture, Vol. 16, No. 2, 2008, pp. 488-494. doi:10.3724/SP.J.1011.2008.00488

[8] H. Liu, Q. Wang, Y. Song, et al., "Evaluating Regional Circular Economy Based on Emergy Theory: A Case Study in Liaoning Province,” Resources Science, Vol. 30, No. 2, 2008, pp.192-198.

[9] Chongqing Bureau of Statistics, "Chongqing Statistical Yearbook (2003-2008),” Chinese Statistical Press.

[10] S. F. Lan, P. Qin and H. F. Lu, "Emergy Analysis of Ecoeconomic System,” Chemical Industry Press, 2002.

[11] R. Q. Wang and X. M. Rong, "Emergy Analysis of Agroeconomic System in Shanxi Province,” Chinese Journal of Applied Ecology, Vol. 19, No. 10, October 2008, pp. 2259-2264.

[12] B. Y. Du, M. X. Men, H. Xu, et al., "Comprehensive Evaluation of Environmental Resources and Farmland Ecosystems in Hebei Province Based on Emergy Theory,” Resources Science, Vol. 30, No. 8, 2008, pp. 12361242.

[13] H. T. Odum, "Environment Accounting: Emergy and Environment Decision Making," John Wiley and Sons, 1995.

[14] H. T. Odum, "Energy, Environment and Public Policy," Oriental Publishing House, 1995.

[15] L. Z. Zhang, Z. F. Yang, B. Chen, et al., “An Analysis on Urban Ecological Competition Capability with Biophysical Accounting Method,” Acta Ecologica Sinica, Vol. 28, No. 9, 2008, pp. 4344-4351.

[16] D. W. Yang, Z. J. Chen, H. Y. Ni, L. Jiang and X. Y. Liao, "Assessment of Sustainability in Eco-economic Systemin Sichuan Province Based on Emergy Analysis," Resources and Environment in the Yangtze Basin, Vol. 15, No. 3, 2006, pp. 303-309. 